\title{
Hemodynamic measurements for evaluating vasovagal syncope in the emergency department
}

\section{Stewart Siu-Wa Chan, Junrong Mo, Colin Alexander Graham, Timothy Hudson Rainer}

Accident and Emergency Medicine Academic Unit, Prince of Wales Hospital, The Chinese University of Hong Kong, Hong Kong

Syncope is a sudden and transient loss of consciousness and postural tone, with spontaneous recovery without medical intervention. It accounts for 1.0\% to 1.5\% of emergency department (ED) visits and up to $6 \%$ of hospital admissions. Vasovagal syncope may be the cause of syncope in $21 \%$ to $40 \%$ of cases. A 53-year-old Chinese woman was brought to the ED by ambulance after a near-syncope episode while performing gentle morning exercises. She was hypotensive and bradycardic in the ambulance. Upon arrival at the ED, her blood pressure was 89/61 $\mathrm{mmHg}$. The use of a Doppler cardiac output monitor readily demonstrated that the patient's systemic vascular resistance was reduced, with cardiac output at the lower limit of the normal range. These hemodynamic data were useful in supporting the diagnosis of vasovagal syncope; they helped in the risk stratification of our patient with syncope, and guided the management and subsequent disposition decision.

Keywords Hemodynamics; Syncope; Ultrasonography, Doppler; Cardiac output

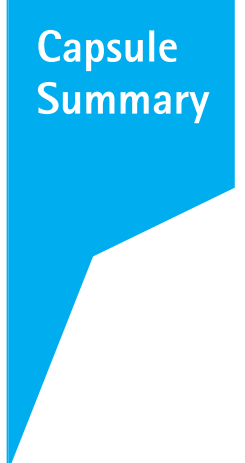

What is already known

Although vasovagal syncope is usually associated with good prognosis, its diagnosis in the ED can be difficult and subjectively based on the interpretation of prodromal symptoms described by patients.

\section{What is new in the current study}

The use of hemodynamic measurements is useful in supporting the diagnosis of vasovagal syncope, and therefore in risk stratification of patients presenting with syncope. This may help the emergency physician in safely avoiding unnecessary hospital admissions.
elSSN: 2383-4625

Received: 31 October 2014

Revised: 11 January 2015

Accepted: 12 January 2015

Correspondence to: Stewart Chan Accident and Emergency Medicine Academic Unit, Prince of Wales Hospital, The Chinese University of Hong Kong, 30-32 Ngan Shing Street, Shatin, NT, Hong Kong

E-mail: stewart_chan@hotmail.com

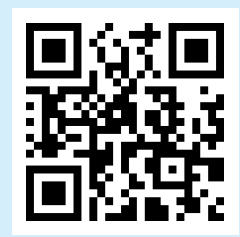

How to cite this article:

Chan SS, Mo J, Graham CA, Rainer TH. Hemodynamic measurements for evaluating vasovagal syncope in the emergency department. Clin Exp Emerg Med 2015;2(1):59-62.

This is an Open Access article distributed under the terms of the Creative Commons Attribution Non-Commercial License (http:// creativecommons.org/licenses/by-nc/3.0/). 


\section{INTRODUCTION}

Syncope is a sudden and transient loss of consciousness and postural tone, with spontaneous recovery without medical intervention. ${ }^{1,2}$ Near-syncope or presyncope occurs when there is a sensation of imminent loss of consciousness, without actual syncope. ${ }^{1}$ Syncope accounts for $1.0 \%$ to $1.5 \%$ of emergency department (ED) visits and up to $6 \%$ of hospital admissions, and is therefore a relatively common problem encountered by emergency physicians. ${ }^{3,4}$ We present a case of vasovagal syncope in which we relied on non-invasive hemodynamic measurements of cardiac output and systemic vascular resistance to support diagnosis and subsequent management.

\section{CASE REPORT}

A 53-year-old Chinese woman with a past medical history of breast carcinoma, deep venous thrombosis, hypertension, and hyperlipidemia was brought to the ED after a near-syncope episode. Immediately prior to the incident, she was performing gentle morning exercises in a standing position, when she felt dizzy, became diaphoretic, and collapsed. She did not have any chest pain or palpitations; and she reported no abdominal pain or recent tarry stool. Serial measurements of blood pressure recorded in the ambulance were low-98/52, 85/48, and 90/47 mmHg; slow heart rates of 52,56 , and $56 \mathrm{bpm}$ from three consecutive measurements were also recorded. Upon arrival at the ED, her blood pressure was $89 / 61 \mathrm{mmHg}$, heart rate was $66 \mathrm{bpm}$, respiratory rate was 16 breaths/min, and oxygen saturation was 99\% on room air. She was alert, fully oriented, and afebrile. On examination, there were no focal neurological deficits indicating localized cerebral or cerebellar dysfunction. Her heart sounds were normal, without murmur or gallop, and her lungs were clear upon auscultation, bilaterally. Her abdomen was soft, non-tender, and with no palpable mass; the remainder of the physical examination was also unremarkable. An electrocardiogram showed sinus rhythm with no ischemic changes. Capillary glucose level was $6.4 \mathrm{mmol} / \mathrm{L}$, and hemoglobin level was $15.9 \mathrm{~g} / \mathrm{dL}$. Venous lactate was $1.4 \mathrm{mmol} / \mathrm{L}$ with a pH of 7.35 and base excess of $1.9 \mathrm{mmol} / \mathrm{L}$. The initial clinical assessment was suggestive of vasovagal syncope, although her hypotension in the context of near-syncope was concerning. Her regular medications were diltiazem (sustained release) 100 $\mathrm{mg}$ daily, lisinopril $20 \mathrm{mg}$ twice daily (bd), gemfibrozil $600 \mathrm{mg}$ bd, and ezetimibe $10 \mathrm{mg}$ daily; these could be responsible at least in part for the hypotension, although there was no recent change in medication.

At this point, hemodynamic measurements were obtained us-
Table 1. Hemodynamic measurements of SV, SVI, CO, Cl, SVR, and SVRI using USCOM at presentation and after 5 hours

\begin{tabular}{lccc}
\hline & $10: 27 \mathrm{hr}$ & $15: 20 \mathrm{hr}$ & Reference range \\
\hline $\mathrm{SV}(\mathrm{mL})$ & 68 & 80 & $63-81$ \\
$\mathrm{SVI}\left(\mathrm{mL} / \mathrm{m}^{2}\right)$ & 37 & 44 & $36-51$ \\
$\mathrm{CO}(\mathrm{L} / \mathrm{min})$ & 4.2 & 4.7 & $4.2-5.9$ \\
$\mathrm{Cl}\left(\mathrm{L} / \mathrm{min} / \mathrm{m}^{2}\right)$ & 2.3 & 2.6 & $2.4-3.7$ \\
SVR $\left(\mathrm{d} . \mathrm{m} . \mathrm{cm}^{-5}\right)$ & 988 & 1,541 & $1,084-1,587$ \\
SVRI $\left(\mathrm{d} . \mathrm{m}^{-5} \mathrm{~cm}^{-5} \mathrm{~m}^{2}\right)$ & 1,793 & 2,798 & $1,712-2,766$ \\
\hline
\end{tabular}

SV, stroke volume; SVI, stroke volume index; $\mathrm{CO}$, cardiac output; $\mathrm{Cl}$, cardiac index; SVR, systemic vascular resistance; SVRI, systemic vascular resistance index.

ing a non-invasive ultrasonic cardiac output monitor (USCOM; Uscom Ltd., Sydney, Australia). ${ }^{5}$ Hemodynamic parameters including stroke volume, cardiac output, and systemic vascular resistance, and their indices with reference to body surface area are shown in Table 1. In this clinical context, the hemodynamic data supported the diagnosis of vasovagal syncope, with cardiac output at the lower limit of normal, and systemic vascular resistance reduced.

A bolus dose of intravenous atropine, $0.6 \mathrm{mg}$, was then given together with a normal saline $500 \mathrm{~mL}$ fluid bolus. Five minutes later, blood pressure and heart rate returned to normal at 111/71 $\mathrm{mmHg}$ and $86 \mathrm{bpm}$, respectively. Stabilization of vital signs allowed the patient to be transported out of the ED high dependency unit. At the end of about five hours of observation, the patient had remained asymptomatic, with blood pressure at $128 / 73 \mathrm{mmHg}$ and heart rate at $59 \mathrm{bpm}$. A repeat USCOM showed that her hemodynamic measurements had returned to normal (Table 1). Renal and liver functions and complete blood count results were also normal; cardiac troponin was not elevated, and she was discharged home with a diagnosis of vasovagal syncope.

\section{DISCUSSION}

Vasovagal syncope (neurally mediated syncope) has been found to be a cause of syncope in at least 21\% (and up to 40\%) of cases in several major studies. ${ }^{2,6-8}$ The ability to rapidly confirm or increase the confidence of a vasovagal syncope diagnosis is therefore important in risk stratification, since this condition is consistently associated with a good prognosis. ${ }^{6}$ The Bezold-Jarisch reflex is the most commonly used model to explain the neurally mediated response in the pathophysiology of vasovagal syncope., Excessive venous pooling in the lower body, in most instances from the upright position, triggers a chain of events culminating in vasodilatation and bradycardia (instead of the normal physiological response of vasoconstriction and tachycardia). This is mediated through a decrease in the sympathetic outflow to the heart 
and vasculature with an increase in parasympathetic activity. Typically, vasovagal syncope is associated with a precipitating event, such as emotional stress, fear, severe pain, or instrumentation. ${ }^{9}$ Many authorities consider orthostatic syncope also as one form of vasovagal syncope. ${ }^{9}$ In this case, the finding of low cardiac output with reduced systemic vascular resistance is confirmatory of the suspicion of vasovagal syncope. The only other conditions that would have given rise to this pattern of hemodynamic abnormality would be neurogenic shock and late stage septic shock, both of which clearly did not correlate with the clinical presentation of this patient. Of note, the finding of reduced systemic vascular resistance is useful in that it essentially rules out cardiogenic shock and hypovolemic shock, as both these conditions are associated with vasoconstriction instead of vasodilatation.

The diagnosis of vasovagal syncope according to prodromal symptoms can be problematic because of inconsistency and subjectivity in interpretations among physicians. A recent international expert consensus on the risk stratification of syncope in the ED identified the need for research on emerging diagnostics that could provide prognostic information. ${ }^{10}$ In the reported case, hemodynamic measurements helped us in the diagnosis and risk stratification of this case, and further guided our disposition decision. By contrast, based on the San Francisco Syncope Rule, admission would have been recommended, because the patient's hypotension, with systolic blood pressure below $90 \mathrm{mmHg}$ at the time of triage, would have categorized her as at high risk of adverse events. ${ }^{411}$ Applying the San Francisco Syncope Rule to this case of near-syncope is justified, since both syncopal and presyncopal events were included in the derivation of the rule. ${ }^{4}$ This rule is one of the most referenced clinical prediction rules validated for syncope, yet it is limited by a low specificity $(56 \%)$ in predicting short-term adverse events. ${ }^{1{ }^{14}}$ Its specificity from an external validation study was even lower (42\%), while the specificity based on physician's judgment was 52\%., ${ }^{411,12}$ The low specificity implies many false positives or unnecessary hospital admissions. Our reported case illustrates how hemodynamic measurements may increase the specificity of the San Francisco Syncope Rule or physician's judgment in the evaluation of syncope. This may help physicians in safely reducing unnecessary hospital admissions.

Fig. 1 shows an emergency physician using USCOM to obtain hemodynamic measurements of a patient. USCOM uses continuous wave Doppler ultrasound transcutaneously to detect the velocity of blood flowing through the aortic valve or pulmonary valve. The time to read-out is less than 3 minutes. A recent metaanalysis of the accuracy and precision of USCOM showed that it attained a pool-weighted percentage error that was comparable to other non-invasive or minimally invasive cardiac output moni-

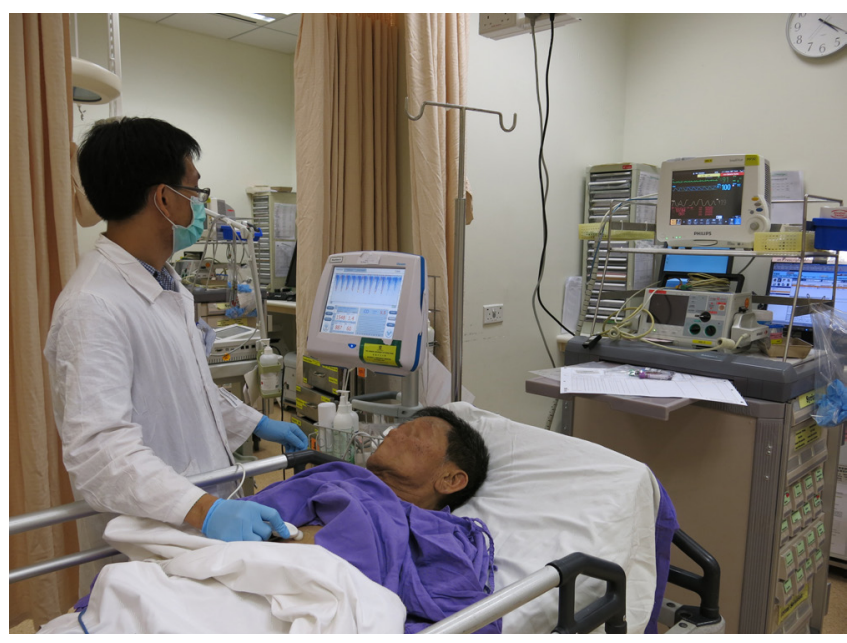

Fig. 1. An emergency physician uses USCOM to obtain data regarding hemodynamic parameters of a patient.

toring devices. ${ }^{13}$ Another non-invasive device, the Nexfin (BMEYE, Amsterdam, the Netherlands), which utilizes a finger-cuff technology based on the pulse contour method, can also be conveniently applied in the ED to obtain hemodynamic measurements. ${ }^{14}$ Impedance cardiography has also been utilized to improve physician estimation of hemodynamic parameters in the ED. ${ }^{15}$

In conclusion, hemodynamic measurements may be used to support the diagnosis of vasovagal syncope and are useful in the risk stratification of patients who present to the ED with syncope or near-syncope. More research is needed to determine how these prognostic concepts can be incorporated into an ED-based observation protocol.

\section{CONFLICT OF INTEREST}

No potential conflict of interest relevant to this article was reported.

\section{REFERENCES}

1. Kessler C, Tristano JM, De Lorenzo R. The emergency department approach to syncope: evidence-based guidelines and prediction rules. Emerg Med Clin North Am 2010;28:487-500.

2. Sarasin FP, Louis-Simonet $M$, Carballo $D$, et al. Prospective evaluation of patients with syncope: a population-based study. Am J Med 2001;111:177-84.

3. Blanc JJ, L'Her C, Touiza A, Garo B, L'Her E, Mansourati J. Prospective evaluation and outcome of patients admitted for syncope over a 1 year period. Eur Heart J 2002;23:815-20.

4. Quinn JV, Stiell IG, McDermott DA, Sellers KL, Kohn MA, Wells GA. Derivation of the San Francisco Syncope Rule to predict 
patients with short-term serious outcomes. Ann Emerg Med 2004;43:224-32.

5. Meyer S, Todd D, Wright I, Gortner L, Reynolds G. Non-invasive assessment of cardiac output with portable continuous-wave Doppler ultrasound. Emerg Med Australas 2008;20:201-8.

6. Soteriades ES, Evans JC, Larson MG, et al. Incidence and prognosis of syncope. N Engl J Med 2002;347:878-85.

7. Ammirati F, Colivicchi F, Santini M. Diagnosing syncope in clinical practice: implementation of a simplified diagnostic algorithm in a multicentre prospective trial. The OESIL 2 study (Osservatorio Epidemiologico della Sincope nel Lazio). Eur Heart J 2000;21:935-40.

8. Fenton AM, Hammill SC, Rea RF, Low PA, Shen WK. Vasovagal syncope. Ann Intern Med 2000;133:714-25.

9. Tan MP, Parry SW. Vasovagal syncope in the older patient. J Am Coll Cardiol 2008;51:599-606.

10. Sun BC, Costantino G, Barbic $F$, et al. Priorities for emergency department syncope research. Ann Emerg Med 2014;64:64955.e2.
11. Quinn J, McDermott D, Stiell I, Kohn M, Wells G. Prospective validation of the San Francisco Syncope Rule to predict patients with serious outcomes. Ann Emerg Med 2006;47:44854.

12. Quinn JV, Stiell IG, McDermott DA, Kohn MA, Wells GA. The San Francisco Syncope Rule vs physician judgment and decision making. Am J Emerg Med 2005;23:782-6.

13. Chong SW, Peyton PJ. A meta-analysis of the accuracy and precision of the ultrasonic cardiac output monitor (USCOM). Anaesthesia 2012;67:1266-71.

14. Nowak RM, Sen A, Garcia AJ, et al. The inability of emergency physicians to adequately clinically estimate the underlying hemodynamic profiles of acutely ill patients. Am J Emerg Med 2012;30:954-60.

15. Neath SX, Lazio L, Guss DA. Utility of impedance cardiography to improve physician estimation of hemodynamic parameters in the emergency department. Congest Heart Fail 2005;11:1720. 